\section{Ketorolac and indomethacin are equally efficacious for the relief of minor postoperative pain}

Patricia Morley-Forster FRCPC, Peter T. Newton MD, Mary-Jo Cook RN
Injectable ketorolac is an effective analgesic in ambulatory surgery patients. However, no studies have compared ketorolac with other NSAIDs in this setting. The analgesic efficacy of intramuscular ketorolac, rectal indomethacin and placebo was compared in healthy women undergoing gynaecological or breast surgery as outpatients. Ninety patients received $30 \mathrm{mg}$ im ketorolac, $100 \mathrm{mg}$ pr indomethacin or placebo in a prospective, randomized, double-blind manner. A standardized anaesthetic protocol was followed. Patients graded their pain on a $10 \mathrm{~cm}$ visual analogue scale in the recovery room, twice in the surgical day care unit and during the car ride home. The patients' postoperative fentanyl requirements, time to recovery milestones, and side effects were recorded. The placebo group received more fentanyl in the $P A C U$ but did not achieve the same pain relief as either of the NSAID-treated group (ketorolac $44 \pm 53 \mu \mathrm{g}$, indomethacin $39 \pm 55 \mu \mathrm{g}$, placebo $87 \pm 100$ $\mu \mathrm{g}, P<0.05)$. Patients who received an NSAID had less pain at 15 and $90 \mathrm{~min}(P<0.05)$. The $P A C U$ stay was longer for the placebo group (ketorolac $50 \pm 13 \mathrm{~min}$, indomethacin $49 \pm 12 \mathrm{~min}$, placebo $62 \pm 35 \mathrm{~min}, P<0.05$ ). Time to ambulation was also longer in the placebo group (ketorolac 117 $\pm 25 \mathrm{~min}$, indomethacin $121 \pm 49 \mathrm{~min}$, placebo $140 \pm 51$ $\min , P<0.05$ ). However, no differences were observed between

\section{Key words}

ANALGESIA: postoperative;

ANALGESICS: non-steroidal antiinflammatory drugs, indomethacin, ketorolac;

PAIN: postoperative;

SURGERY: ambulatory.

From the Department of Anaesthesia, St. Joseph's Health Centre, University of Western Ontario, London, Ontario, Canada N6A 4V2

Supported by a grant from St. Joseph's Health Centre Foundation.

Abstract presented at A.S.A. meeting, New Orleans, October 19-23, 1992.

Address correspondence to: Dr. P. Morley-Forster. Accepted for publication 30th July, 1993. the two NSAIDS. Side effects were similar in all groups. We conclude that im ketorolac and pr indomethacin are equally effective analgesics in this group of patients.

Le kétorolac injectable est un analgésique efficace en chirurgie ambulatoire. Cependant, aucune étude ne compare le kétorolac avec les AINS utilisés sous les mêmes conditions. Cette étude compare l'efficacité analgésique du kétorolac intramusculaire, de lindométhacine rectale et d'un placébo chez des patientes ambulatoires non tarées soumises à une chirurgie gynécologique ou mammaire. Au cours d'une étude prospective, randomisée et à double insu, 90 patientes reçoivent du kétorolac $30 \mathrm{mg}$ im, de l'indométhacine $100 \mathrm{mg}$ pr ou un placébo. Un protocole anesthésique standard est utilisé. Les malades évaluent leur douleur sur une échelle visuelle analogue de $10 \mathrm{~cm}$ à la salle de réveil, deux fois dans le centre de soins de chirurgie d'un jour et pendant le retour en automobile vers le domicile. Les besoins en fentanyl postopératoire, les incidents du réveil et les effets secondaires sont notés. Les patientes du groupe placébo reçoivent plus de fentanyl à la salle de réveil et sont moins soulagées que les deux groupes traités aux AINS (kétorolac $44 \pm 53 \mu \mathrm{g}$, indométhacine $39 \pm 55 \mu \mathrm{g}$, placébo $87 \pm 100$ $\mu g, P<0,05)$. Le délai précédant l'ambulation est aussi prolongé dans le groupe placébo (kétorolac $117 \pm 25 \mathrm{~min}$, indométhacine $121 \pm 49 \mathrm{~min}$, placébo $140 \pm 51 \mathrm{~min}, P<0,05$ ). Toutefois, on ne trouve pas de différence entre les deux groupes AINS. Les effets secondaires sont les mêmes. Nous concluons que le kétorolac im et l'indométhacine pr sont des analgésiques d'une efficacité égale pour notre groupe de patientes.

Non-steroidal anti-inflammatory drugs have been used for postoperative analgesia since the early 1970's. ${ }^{1-3}$ Many anaesthetists first became aware of the efficacy of NSAIDs for postoperative pain relief when injectable ketorolac tromethamine was released on the North American market. Intramuscular ketorolac $30 \mathrm{mg}$ has been shown to be as efficacious as morphine $12 \mathrm{mg}$ and superior to morphine $6 \mathrm{mg}$ im for the relief of moderate to severe postoperative pain. ${ }^{4}$ 
Indomethacin has been proved to provide effective analgesia postoperatively either as the sole agent ${ }^{5}$ or in conjunction with opioids. ${ }^{6,7}$ The onset time of $20-30 \mathrm{~min}$ for an indomethacin suppository ${ }^{8}$ is equivalent to the onset time of im ketorolac. ${ }^{9}$

Although there are many studies comparing ketorolac with other opioids, there are very few comparisons of ketorolac with other NSAIDs. In a prospective, randomized, double-blind trial we compared the efficacy of im ketorolac and $p r$ indomethacin for pain relief after outpatient surgery.

\section{Methods}

Approval for this study was granted by the institutional review board. The subjects studied were women aged 18-65 yг, ASA 1-2 undergoing diagnostic laparoscopy, laser conization of cervix for carcinoma in situ, or breast biopsy. Exclusion criteria were a history of possible pregnancy, lactation, NSAID sensitivity, coagulopathy, narcotic abuse, or a history of previous peptic ulcer disease.

After written, informed consent had been obtained, subjects were brought to the operating room fasting and unpremedicated. In the operating room, routine monitors were applied and a standard anaesthetic protocol was followed in all patients. Induction consisted of fentanyl $1 \mu \mathrm{g} \cdot \mathrm{kg}^{-1}$, propofol $2-3 \mathrm{mg} \cdot \mathrm{kg}^{-1}$. If intubation was planned, d-tubocurarine $3 \mathrm{mg}$ was given as a defasciculant three minutes before succinylcholine $1.5 \mathrm{mg} \cdot \mathrm{kg}^{-1}$. Anaesthesia was maintained with nitrous oxide $50 \%$ in oxygen, isoflurane $1-2 \%$, and atracurium $0.3 \mathrm{mg} \cdot \mathrm{kg}$ as needed for muscle relaxation.

After induction, each patient was randomly assigned to one of three groups. The hospital pharmacy prepared the randomization table and all study drugs and placebos beforehand. One group (KET) received $30 \mathrm{mg}$ ketorolac im and a placebo suppository; the second group (IND) received $100 \mathrm{mg}$ indomethacin $\mathrm{pr}$ and a placebo injection; the third group (PLAC) received both a placebo injection and a placebo suppository. At the completion of surgery, neuromuscular blockade was reversed with a standard dose of glycopyrrolate and neostigmine.

Subjects were transferred awake to the Post-anaesthetic Care Unit (PACU). In the PACU, intravenous fentanyl $50 \mu \mathrm{g} \mathrm{q} 15 \mathrm{~min}$ was administered by the research nurse if the patient requested analgesia. Standard visual analogue pain scores were obtained at 15,60 , and $90 \mathrm{~min}$ after emergence from anaesthesia as well as during the ride home. The patient marked their degree of pain on an open-ended horizontal $10 \mathrm{~cm}$ line with 0 being no pain and 10 being the worst pain imaginable. The first postoperative pain score was obtained before administration of any fentanyl. The patients recorded their subjective feeling of sedation on a visual analogue sedation
TABLE I Demographic data for the three treatment groups

\begin{tabular}{llll}
\hline Variable & $\begin{array}{l}\text { Ketorolac } \\
n=31\end{array}$ & $\begin{array}{l}\text { Indomethacin } \\
n=31\end{array}$ & $\begin{array}{l}\text { Placebo } \\
n=25\end{array}$ \\
\hline Age (yr) & $37 \pm 14$ & $35 \pm 8$ & $35 \pm 11$ \\
Wt (kg) & $62 \pm 13$ & $65 \pm 13$ & $67 \pm 14$ \\
OR time (min) & $20 \pm 14$ & $20 \pm 11$ & $18 \pm 11$ \\
Diagnostic laparoscopy/ & & & \\
$\quad$ cervical conization & 24 & 27 & 25 \\
Breast surgery & 7 & 4 & 0 \\
No. intubated & 10 & 10 & 13 \\
\hline
\end{tabular}

scale with 0 being completely alert and 10 being asleep. The total amount of fentanyl administered in the PACU was recorded.

Patients were discharged from the PACU at the discretion of the nurses using the usual criteria of adequately controlled pain and a post-anaesthetic recovery room (PARR) score greater than 7 out of 10 . The PARR score assesses patient colour, respiration, circulation, consciousness, and activity each on a scale of 0-2 giving a maximum possible total of 10 . Patients were discharged home from the Surgical Day Care Unit (SDCU) when they were able to walk unassisted and could tolerate oral fluids. The times to these recovery milestones were noted as well as duration of stay in PACU and total postoperative stay. Side effects of nausea or vomiting, drowsiness, dizziness, itching and rectal fullness were recorded.

The pain and sedation scores, PARR scores and recovery milestones were analyses using analysis of variance (ANOVA). The pain scores were subjected to $a$ priori contrast of NSAID groups vs placebo. Fentanyl requirements were compared with one-way ANOVA. The incidence of side effects was tested using Chi square analysis with Fisher's exact test where appropriate. Data are presented as means $\pm \mathrm{SD}$.

\section{Results}

Of 93 women approached regarding this study, 90 agreed to participate. Three patients were excluded from analysis for failure to follow the anaesthetic protocol of the study. This left 31 patients in the ketorolac group, 31 in the indomethacin group and 25 in the placebo group. The groups were similar with regards to age, weight, type and duration of surgery (Table I).

Both of the groups treated with an NSAID required less fentanyl than the placebo group $(P<0.05)$ but there was no difference in postoperative narcotic consumption between the KET and IND groups (KET $44 \pm 53 \mu \mathrm{g}$, IND $39 \pm 55 \mu \mathrm{g}$, PLAC $87 \pm 100 \mu \mathrm{g}, P<0.05$ ).

Postoperative pain scores were lower at 15 and $90 \mathrm{~min}$ in patients who received NSAID $(P<0.05)$ but no different at $60 \mathrm{~min}$ or on the way home (Figure 1). Pain 


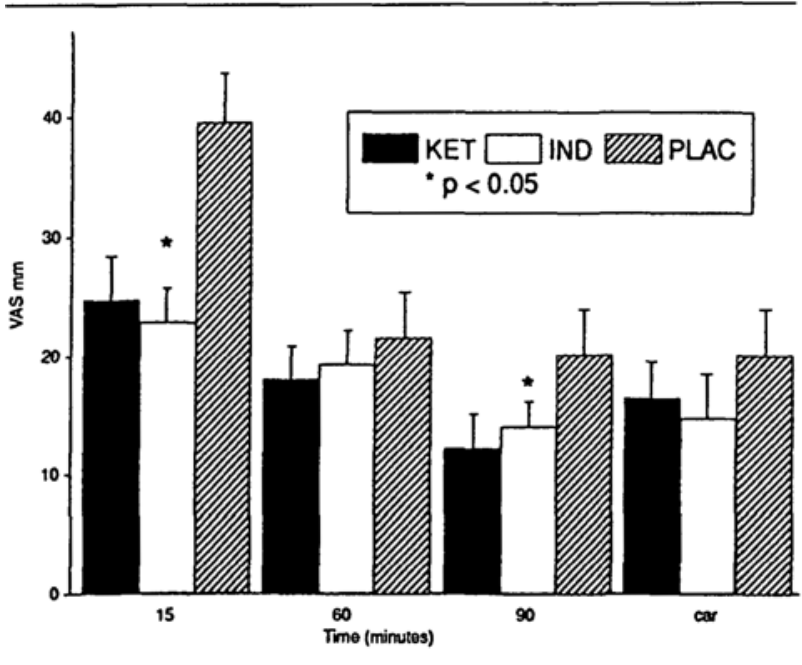

FIGURE I Postoperative pain scores. Mean pain scores ( \pm SEM) at $15,60,90 \mathrm{~min}$ postoperatively and on the car ride home. ${ }^{*}$ Placebo group significantly different. $P<0.05$.

scores were similar in the ketorolac and indomethacin groups at all times.

Sedation analogue scores showed no inter-group differences at any time (Figure 2).

The time spent in recovery room and the time to ambulation were shorter in the NSAID-treated groups $(P$ $<0.05$, Table II) with no difference between the ketorolac and indomethacin groups. Time to oral intake and total postoperative stay were the same in all three groups.

The overall incidence of side effects was low and showed no differences among groups (Table III).

\section{Discussion}

Non-steroidal anti-inflammatory drugs improved outcome in this group of surgical outpatients by reducing postoperative pain and shortening recovery times in comparison with the control group. Their analgesic efficacy is related to their ability to reduce prostaglandin accumulation at the site of surgical trauma.

Cell membrane injury leads to release of bradykinin, histamine, and arachidonic acid. All NSAIDs inhibit cyclooxygenase, the enzyme required to convert arachidonic acid to prostaglandins. Prostaglandins facilitate inflammation by potentiating bradykinin and histamine producing a zone of hyperalgesia to both mechanical and thermal stimuli at the injured site. ${ }^{10}$ In addition, prostaglandins stimulate pain receptors to release Substance $\mathrm{P}$, a potent inflammatory mediator, from cell bodies of sensory nerve fibres. "

Indomethacin suppositories $100 \mathrm{mg} \mathrm{q} 8 \mathrm{~h}$ were reported by Reasbeck et al. in 1982 to be an effective adjunct to opioid analgesia for abdominal surgery. ${ }^{6}$ Other studies

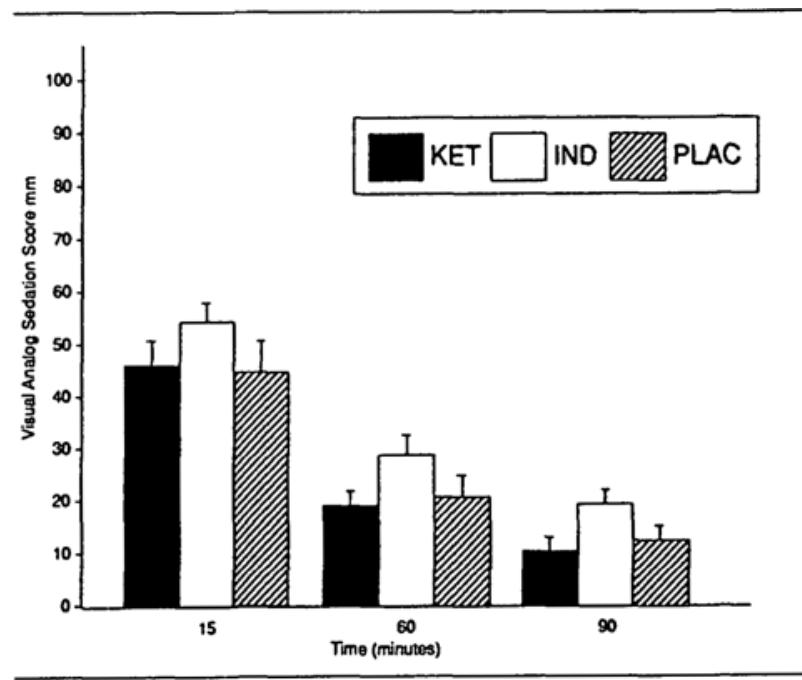

FIGURE 2 Postoperative sedation scores. Mean sedation scores $( \pm$ SEM) at 15, 60 and 90 min postoperatively. (NS).

TABLE II Comparison of recovery milestones among the three groups

\begin{tabular}{lrcc}
\hline & Ketorolac & Indomethacin & Placebo \\
\hline PACU time (min) & $50 \pm 13$ & $49 \pm 12$ & $62 \pm 35^{*}$ \\
Time to liquids (min) & $50 \pm 16$ & $47 \pm 21$ & $57 \pm 33$ \\
Time to stand (min) & $117 \pm 25$ & $121 \pm 49$ & $140 \pm 51^{*}$ \\
Total postop stay (min) & $148 \pm 35$ & $151 \pm 46$ & $167 \pm 54$ \\
\hline
\end{tabular}

*Statistically significant to $P<0.05$.

TABLE III Side effects experienced in the three treatment groups

\begin{tabular}{llll}
\hline Side effects & $\begin{array}{l}\text { Ketorolac } \\
n=31\end{array}$ & $\begin{array}{l}\text { Indomethacin } \\
n=31\end{array}$ & $\begin{array}{l}\text { Placebo } \\
n=25\end{array}$ \\
\hline Nausea/vomiting & 3 & 3 & 5 \\
Drowsiness & 2 & 4 & 1 \\
Dizziness & 1 & 0 & 1 \\
Itching & 0 & 0 & 1 \\
Rectal fullness & 1 & 2 & 0 \\
\hline
\end{tabular}

No statistical difference in side effects among the three treatment groups.

using different postoperative pain models have confirmed this finding. ${ }^{12,13}$ The dose required for analgesia is higher than that required for anti-inflammatory activity. ${ }^{14}$

Ketorolac $30 \mathrm{mg} \mathrm{im}$ has been shown to be equivalent to $12 \mathrm{mg}$ morphine im and $100 \mathrm{mg}$ meperidine im. ${ }^{9} \mathrm{Sug}$ gested reasons for its analgesic potency are that it blocks both cyclooxygenase and lipooygenase preventing synthesis of both prostaglandins and leukotrienes. ${ }^{15}$ Another hypothesis, supported by animal work, is that ketorolac may cause the release of endogenous opioids. ${ }^{16}$

We compared ketorolac im and indomethacin pr be- 
cause they share a similar onset time of 20 to $30 \mathrm{~min}$. Both can be given just after induction of anaesthesia and produce reliable postoperative analgesia even for short procedures. Injectable indomethacin is not available in North America for im injection.

In this study, surgical incision occurred almost immediately after NSAID administration so that their beneficial postoperative effects can not be attributed to preemptive analgesia. Murphy and Medley found, in thoracotomy patients, that the quality of pain relief and reduction in postoperative opioid requirements was the same whether indomethacin was given the night before or at the conclusion of surgery. ${ }^{17}$ One of their hypotheses was that the central sensitization to pain outweighed the peripheral effect of prostaglandin inhibition.

Preoperative oral NSAIDs have been used successfully to alleviate pain and reduce discharge times after laparoscopic tubal occlusion. ${ }^{18,19}$ Brown et al. have shown that a single oral preoperative dose of $550 \mathrm{mg}$ of naproxen sodium was as effective at one hour postoperatively in gynaecological, orthopaedic and general surgical patients as a single injection of $10 \mathrm{mg}$ of morphine. ${ }^{20}$ The potential problems with oral, as opposed to parenteral, NSAIDs are a delayed and unpredictable onset, and a higher incidence of gastric irritation when given on an empty stomach.

The incidence of side effects in the NSAID-treated groups was no different from that of the placebo group. However, we excluded patients with a history of previous ulcer disease or coagulopathy.

Ketorolac does not appear to offer any advantage in this postoperative pain model over rectal indomethacin. While and Watcha have pointed out in a recent editorial the need for cost-benefit assessment of new drugs. ${ }^{21} \mathrm{Ke}-$ torolac, although unquestionably a potent NSAID, may not be required to control pain of minor to moderate severity. Ketorolac should be compared with other NSAIDs at equipotent dosages to allow clinicians to decide on the best postoperative analgesia at the lowest cost.

\section{Acknowledgements}

The authors would like to thank the PACU nurses at St. Joseph's Health Centre for their help in completing this study.

\section{References}

1 Kweekel-DeVries WJ, Spierdijk J, Mattie H, Hermans $J M H$. A new soluble acetylsalicylic acid derivative in the treatment of postoperative pain. Br J Anaesth 1974; 46: 133-5.

2 Buchanan JM, Halshaw J, Baldasera J, Dallard JK, Poole $P H$. Postoperative pain relief: a new approach: narcotics compared with non-steroidal anti-inflammatory drugs. Ann R Coll Surg Engl 1988; 70: 332-5.

3 Owen H, Glavin RJ, Shaw NA. Ibuprofen in the management of postoperative pain. Br J Anaesth 1986; 58: 1371-5.

4 O'Hara DA, Fragen RJ, Kinzer M, Pemberton D. Ketorolac tromethamine as compared with morphine sulfate for treatment of postoperative pain. Clin Pharmacol Ther 1987; 41: 556-61.

5 Mattila MAK, Ahlström-Bengs E, Pekkola P. Intravenous indomethacin or oxycodone in prevention of postoperative pain. BMJ 1983; 287: 1026.

6 Reasbeck PG, Rice ML, Reasbeck JC. Double-blind controlled trial of indomethacin as an adjunct to narcotic analgesia after major abdominal surgery. Lancet 1982; 2 : $115-8$

7 Segstro R, Morley-Forster PK, Lu G. Indomethacin as a postoperative analgesic for total hip arthroplasty. Can $J$ Anaesth 1991; 38: 578-81.

8 Holt LPJ, Hawkins CF. Indomethacin: studies of absorption and of the use of indomethacin suppositories. BMJ 1965; 1: 1354-7.

9 Yee JP, Brown CR, Allbon C, Koshiver JE. Analgesia from intramuscular ketorolac tromethamine compared to morphine in severe pain following major surgery. Pharmacotherapy 1986; 6: 253-61.

10 Dahl JB, Kehlet $H$. Non-steroidal anti-inflammatory drugs: rationale for use in severe postoperative pain. $\mathrm{Br} \mathbf{J}$ Anaesth 1991; 66: 703-12.

11 Coderre TJ. Physiologic consequences of tissue injury and acute pain. In: Sandler AN (Ed.). Anesthesiology Clinics of North America. Philadelphia: WB Saunders, 1992, 253.

12 Yrjölä H, Silvennoinen T, Vilppula E, Ahlström-Bengs E. Intravenous indomethacin for postoperative pain: a doubleblind study of ankle surgery. Acta Orthop Scand 1988; 59: 43-5.

13 Thind $P$, Sigsgaard $T$. The analgesic effect of indomethacin in the early post-operative period following abdominal surgery. Acta Chir Scand 1988; 154: 9-12.

14 Beaver WT. Impact of non-narcotic oral analgesics on pain management. Am J Med 1988; 84 (Suppl 5A): 3-15.

15 Hyers TM, Tricomi SM, Liao J-J. Inhibition of some human neutrophil functions by the cyclooxygenase inhibitor ketorolac tromethamine. J Leukoc Biol 1992; 51: 490-5.

16 Domer $F$. Characterization of the analgesic activity of ketorolac in mice. Eur J Pharmacol 1990; 177: 127-35.

17 Murphy DF, Medley C. Preoperative indomethacin for pain relief after thoracotomy: comparison with postoperative indomethacin. Br J Anaesth 1993; 70: 298-300.

18 Rosenblum M, Weller RS, Conard PL, Falvey EA, Gross $J B$. Ibuprofen provides longer lasting analgesia than fentanyl after laparoscopic surgery. Anesth Analg 1991; 73: 255-9. 
19 Comfort VK, Code WE, Rooney ME, Yip RW. Naproxen premedication reduces postoperative tubal ligation pain. Can J Anaesth 1992; 39; 349-52.

20 Brown $C R$, Sevelius $H$, Wild $V$. A comparison of single doses of naproxen sodium, morphine sulfate, and placebo in patients with postoperative pain. Current Therapeutic Research 1984; 35: 511-8.

21 White PF, Watcha $M F$. Are new drugs cost-effective for patients undergoing ambulatory surgery? (Editorial). Anesthesiology 1993; 78: 2-5. 